\title{
Solar energy, wind energy and storage for the electricity grid of today and tomorrow
}

\author{
Filippo Spertino ${ }^{1, *}$, and Alessandro Ciocia $^{1}$ \\ ${ }^{1}$ Politecnico di Torino, Dip. Energia, corso Duca degli Abruzzi 24,10129 Torino, Italy
}

\begin{abstract}
Photovoltaic (PV) generators and wind turbines (WT) are, nowadays, the most used technologies for power generation. This paper has the primary objective to explain the reasons of this success, in the present and in the future. Secondly, in this paper, an estimation of PV-WT percentage share of the electrical consumption is provided, according to a case study of power generation in southern Italy. The simulation results demonstrate that the PV-WT share can exceed the $40 \%$ threshold, considering about $10 \%$ of the national consumption located in a region where sun shines and wind blows generously.
\end{abstract}

\section{Reasons to adopt the PV and WT technologies in the electricity mix}

The first and well-known reason of the current and future massive development of PV and WT technologies is the abundant amount of solar and wind resources in almost all the world's countries. The solar energy received by the Earth over a year is about 1,000 times more than all human energy consumption [1]. The solar resource is more equally distributed across countries than the wind as a resource, which, in turn, has higher power density. Indeed, wind power density is about 5 $\mathrm{kW} / \mathrm{m} 2$ when the wind blows at $20 \mathrm{~m} / \mathrm{s}$ (a rare condition), whereas solar irradiance can reach 1.2 $\mathrm{kW} / \mathrm{m} 2$ in particularly clear sky conditions in mountain locations.

Another reason to choose the PV technology is represented by stable and remarkable values of energy return on energy invested (EROI, elsewhere used as EROEI) in comparison with the fossil fuels and nuclear technologies which tend to decrease their EROI. Two articles give detailed EROI values for PV technologies. The first study [2] provides a systematic review of energy payback time (EPBT) and EROI metrics. The mean harmonised EPBT varied from 1.0 to 4.1 years; the module types ranked in the following order from lowest to highest: cadmium telluride (CdTe), copper indium gallium diselenide (CIGS), amorphous silicon (a:Si), poly-crystalline silicon (poly-Si), and mono-crystalline silicon (mono-Si). The mean harmonised EROI varied from 8.7 to 34.2 .

The second study [3] gives fast and simple methods for estimating the energy required for producing the PV array. To this end, two simple approximations will be introduced, one thought to underestimate the energy cost (embodied energy) and the other thought to overestimate it. Using the upper boundary for the required input energy and allowing for module degradation suggests that the EROI of a PV module would have a lower boundary of 5 or 6 . In short, the world's future generation of PV electricity appears not to be limited by EROI.

The depletion of raw materials in multiple industrial sectors causes serious concern about future growth, but the raw material, used for both WT blades and PV cells [4], silica and purified amorphous/crystalline products, is almost inexhaustible, with negligible costs.

BNEF (Bloomberg Finance) calculates the levelised cost of electricity (LCOE) for each technology, taking into account everything from equipment, construction and financing costs to operating and maintenance expenses and average running hours [5]. In 2018, the benchmark global LCOE was 55 \$/MWh for onshore wind, and 70 \$/MWh for PV without tracking systems. Other studies [6] claim that the LCOE of photovoltaic and wind turbine technologies is today lower than fossil fuel based technologies. BNEF gathers information about the cost of investment for electrochemical batteries (lithium-ion). According to the experience curve technique, already used for PV technologies, the current cost of energy capacity is $300 \$ / \mathrm{kWh}[7]$.

Finally, technological progress and cost-effectiveness are the driving forces of current widespread installation of PV and WT. In 2017, global installed wind power generation was $\approx 540 \mathrm{GW}$ (both land-based and offshore). New annual installation has been relatively constant in recent years $(\approx 50 \mathrm{GW} /$ year $)$. New PV installations are dramatically increasing, however: the world total PV power reached $400 \mathrm{GW}$ in 2017, of which $100 \mathrm{GW}$ was installed in 2017 (more than the combined net capacity additions of fossil fuels and nuclear power). In that year, the world electricity production was $1430 \mathrm{TWh}$ from WT, and $416 \mathrm{TWh}$ from PV [8].

Corresponding author: filippo.spertino@polito.it 


\section{Determination of the optimum PV-WT share without grid reinforcement}

In [9] a procedure is presented to calculate the optimal portfolio of PV generators, WT parks and storage systems which supply the aggregation of several loads. The main goal was to show the advisable self-sufficiency from local renewable energy sources (RES) that can be achieved in grid connection. As shown in Fig. 1, without storage, the self-sufficiency formula is the ratio between the energy locally generated and immediately consumed $E_{\text {lgc }}$, compared to the total load $E_{\text {load }}[10]$.

The energy $E_{\text {load }}$ is thus the sum of the quota $E_{\mathrm{lgc}}$ and absorption from the grid $E_{\text {abs. }}$ If storage is installed, the grid injection $E_{\mathrm{inj}}$ can be stored and used later to increase self-sufficiency.

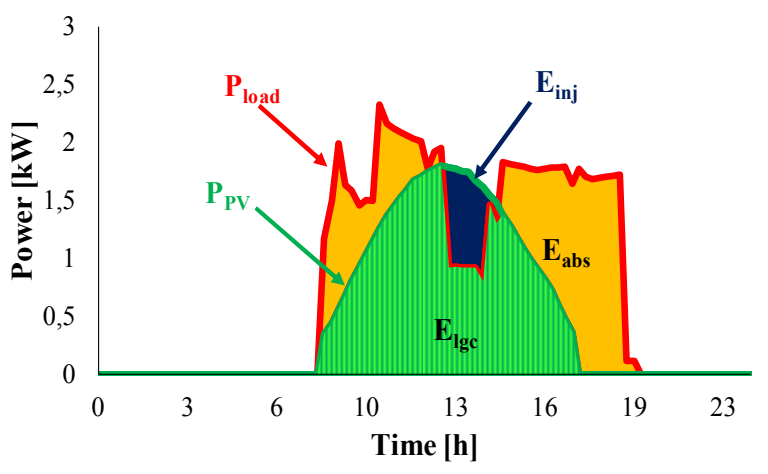

Fig. 1. Example of generation and load profiles to calculate the self-sufficiency ratio.

In order to avoid expensive grid upgrades, RES penetration was limited as a constraint. In addition, only cost-effective investments were considered for the power and energy results. The results, obtained through a comparison between loads and renewable generation in southern Italy, showed that the maximum selfsufficiency could reach $\approx 55 \%$ of the loads, thanks to the use of storage systems. Batteries help the integration of intermittent renewables. Nevertheless, storage costs are still high and for this reason the return on investment is maximised if storage is not used, but the self-sufficiency decreases to $\approx 40 \%$. These results referred to an aggregation of loads with $E_{\text {year }}=530 \mathrm{GWh}$, which is $0.16 \%$ of Italian consumption $\left(E_{\text {year }} \approx 320 \mathrm{TWh}\right)$ in 2017 [11]. Similar work is proposed in the present paper, in which the aggregation of loads corresponds to $\approx 7 \%$ of the Italian consumption profiles, obtained from the transmission system operator (TSO).

\subsection{Load profiles and accurate measurements of irradiance and temperature}

The Italian TSO provides hourly consumption profiles for the third Wednesday of each month [12]. In Italy, in 2017, the maximum consumption was $\approx 54 \mathrm{GW}$, in January, July and in December.

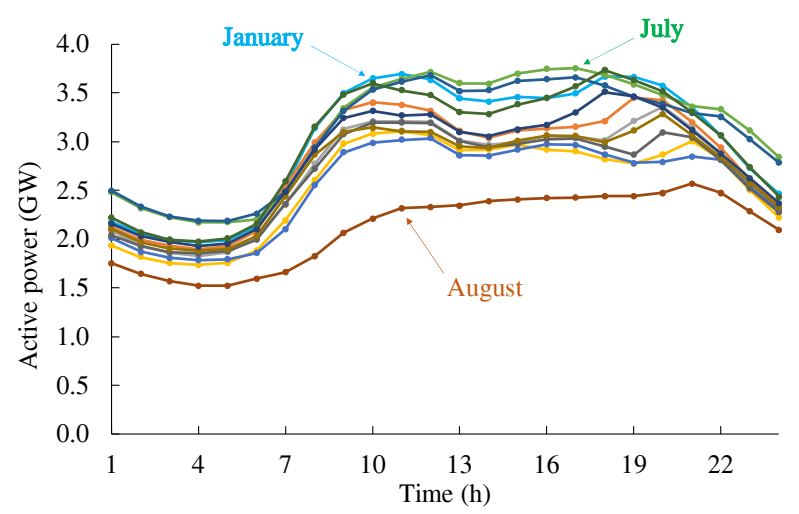

Fig. 2. Consumption profiles for $7 \%$ of the Italian population, 2017.

Consumption decreases dramatically during August. In this month, due to summer holidays, and the consequent cessation of many working activities, the peak load is $\approx 35 \mathrm{GW}$, occurring at 9 p.m.

For the sake of simplicity, the simulations are performed considering load profiles similar to those of the whole country, in the present work. These profiles are weighted according to the population living in Apulia, which is $\approx 7 \%$ of the Italian population. As shown in Fig. 2, the Italian annual load $(\approx 320 \mathrm{TWh})$ is thus scaled down to $\approx 23 \mathrm{TWh}$, and the load profiles are not modified. Furthermore, each one of the twelve daily profiles from the TSO is used as representative of the whole month.

In addition to the load profiles, the other inputs are obtained from meteorological stations located in southern Italy, at latitudes within $39^{\circ}-41^{\circ} \mathrm{N}$, providing data with 1-min time steps.

Irradiances are measured using pyranometers with measurement uncertainty in the range $15-25 \mathrm{~W} / \mathrm{m}^{2}$ [12]. Wind speeds are measured using cup anemometers (good accuracy) at $3 \mathrm{~m}$ height from the ground. Thermohygrometers and barometers are used for air temperature, humidity and pressure.

\subsection{Presentation of the system and simulation procedure}

Fig. 3 shows a simplified scheme of the system under study. It comprises PV generators and WT, used to supply local loads, with the help of a battery energy storage system (BESS). The generators are connected to DC/AC converters to feed AC loads (they are not shown in the scheme). The battery management system (BMS), included in the BESS, manages the charge/discharge cycles and guarantees the correct operation of the batteries. The optimal share in terms of PV, wind turbines and storage is determined by simulating power generation profiles with respect to consumption profiles. This procedure works as follows. Firstly, random sizes are defined for PV, WT and storage, where the term size stands for the rated power for PV and WT, while size means the energy capacity for BESS. 


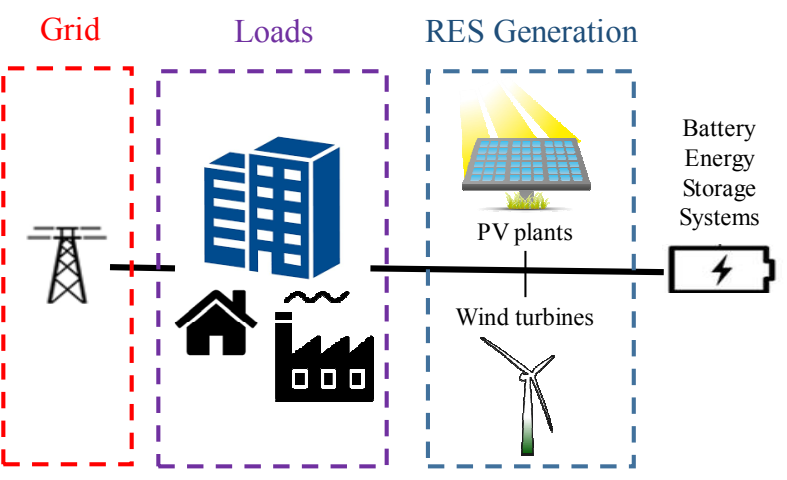

Fig. 3. A simplified scheme of a RES based system under study.

The second step is the calculation of power balances, performed with 1-h time steps for an entire year. The balances consist of comparisons between renewable generation and loads. If the RES production is not enough or is too high for local loads, then BESS is used. If batteries cannot manage all the deficit or surplus, power is exchanged with the grid. All related energy and economic results are stored in a database.

The procedure is repeated for each possible combination of generators and storage sizes. The sizes all start from zero and are increased after each simulation. At the end of all the process, all data set is analysed to exclude unacceptable combinations of generators and storage, according to economic and technical constraints.

\subsection{Simulation constraints}

The first constraint is necessary to avoid grid upgrades: it limits the maximum power that can be injected into the grid. As explained in [13][14][15], the high penetration levels of unpredictable renewables may cause technical issues, such as voltage rises, harmonics and unbalance. For this reason, in order to avoid grid-upgrades, the maximum acceptable power injected into the grid has to be lower than the maximum consumed power over the whole year. In this way, current and power are always under the limits of the grid lines and the annual energy injection cannot be too high.

The second constraint is economic: only costeffective investments are accepted. Investments must have a positive net present value $(\mathrm{NPV}>0)$, and the internal rate of return (IRR), which allows the yields of different investments to be compared, must be higher than $6 \%[16,17]$.

These assumptions are made regarding costs:

- $\quad$ An interest rate $i=3 \%$, this low value can be used for long term investment in renewables with low risk, such as PV and wind turbines.

- An all-inclusive installation cost of $1000 € / \mathrm{kW}$ for PV generators and $1200 € / \mathrm{kW}$ for wind turbines.

- Yearly operation and maintenance (O\&M) costs corresponding to $0.8 \%$ and $2 \%$ of the installation costs, for PV and WT, respectively.

- An initial cost for the BESS, with Li-ion batteries, equal to $300 € / \mathrm{kWh}[18]$.
- An average cost of consumed electricity equal to $\approx 15 \mathrm{c} € / \mathrm{kWh}$.

- An average price paid for the electricity injection into the grid, equal to $\approx 4 \mathrm{c} € / \mathrm{kWh}[19]$.

\subsection{Models for PV generators, WT parks and storage}

The power flow is simulated thanks to appropriate models for PV and wind generators and storage. The energy production from wind turbines is calculated starting from the wind speed measurements. The wind speed is transferred at the height of the WT hub using the formula in [20]. This data is used in the "power output-wind speed" curve, from the datasheet of wind turbines, and the result is a profile of power generation for the entire year [21].

The PV generation profile is calculated starting from solar irradiance and ambient temperature. PV production is calculated according to a proportional model in which power output depends on the two pieces of environmental data noted above, and the PV rated power [22].

The storage operation is calculated by continuously controlling its state of charge (SOC) and the limits in the maximum exchanged power. The quantity of energy that can be charged or discharged is defined according to limits imposed to preserve battery life: storage is full when $\mathrm{SOC}=\mathrm{SOC}$ max , empty when $\mathrm{SOC}=\mathrm{SOC}$ min and these limits cannot be exceeded. The limit of maximum power must also be respected. If it cannot handle the power in the local system, due these power and energy restrictions, the external grid is used to feed the loads.

\subsection{Simulation results}

The simulations of RES generation and consumption profiles allows the optimal sizes of generators and storage to be determined. As an example of the effective integration between PV and WT production, hourly profiles of generation are shown in Fig. 4 for a summer day, where solar and wind resources are complementary. Actually, the wind starts to strongly blow just when the sun is decreasing in afternoon. As a result, the load is fed by RES for more than $15 \mathrm{~h}$ per day. Maximisation of self-sufficiency (M-S-S) reaches $\approx 31 \%$ of the load.

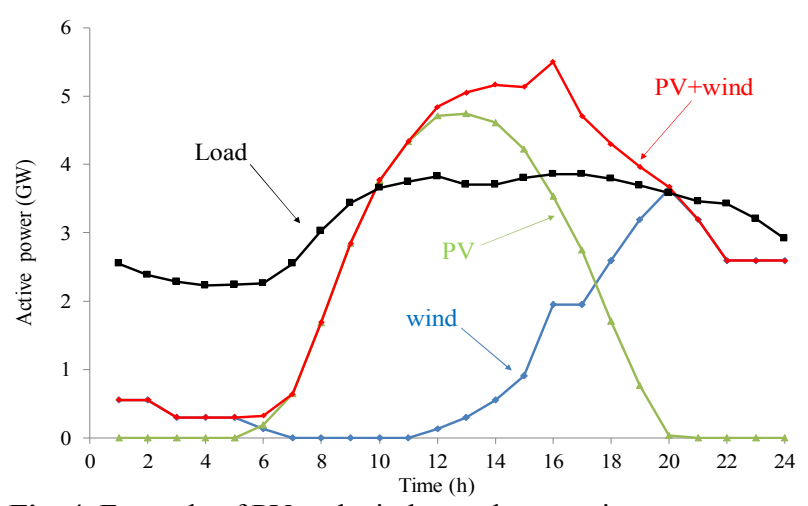

Fig. 4. Example of PV and wind complementarity. 
It is advisable to install $4 \mathrm{GW}$ of PV generators, 1.2 GW of WT parks and a BESS energy capacity of 8 GWh. The computed IRR is $\approx 11 \%$. The size of wind farms is lower than PV generation, because the PV profiles better match the consumption.

On the other hand, in case of the cost-optimal solution, (C-O-S), this self-sufficiency decreases to $26 \%$. The PV size is the same for the previous solution, and WT and BESS have rated powers of $0.4 \mathrm{GW}$ and 4 $\mathrm{GWh}$, respectively. The reduction in the storage installation is due to its high cost; as a consequence, a high WT size cannot be installed to avoid high injections. The above results involve load profiles, and the August load level is almost 50\% less than the other months, due to the work interruption (typical Italian holidays). This low load does not match the high PV production in an adequate way, resulting in imposed limits to the PV and WT sizes to prevent high power injection into the grid. Nevertheless, in the near future there will be a better match between PV production and consumption for the widespread use of heat pumps during August. In this scenario the previous simulations are repeated without including the August load profile. In the case of M-S-S, self-sufficiency reaches $\approx 44 \%$ of the load. A high storage capacity $(20 \mathrm{GWh})$ supports the installation of $6 \mathrm{GW}$ of PV generators and $1.7 \mathrm{GW}$ of WT parks. In the case of C-O-S, the self-sufficiency is $\approx 37 \%$, obtained with a BESS energy capacity of 12 GWh. In both cases, energy injection into the grid is negligible. Regarding the cost-effectiveness of the two investments, the IRR of the M-S-S is 7\%, and $11 \%$ for C-O-S.

\section{Conclusions}

The current technical improvements and the economies of scale today allow, in locations where the sun shines and wind blows, the costs of electricity from PV and WT technologies are lower than fossil fuel and nuclear power plants. The storage technologies needed for compensating for RES intermittency, also demonstrate decreasing costs in energy capacity, down to $300 \$ / \mathrm{kWh}$.

In some countries, the PV/WT share has now exceeded $20 \%$ of the total loads, however, the simulations in the literature and those presented in this paper agree that higher shares can be achieved. In the proposed case study, the maximum self-sufficiency is $\approx 30 \%$. This level is relatively poor, because it includes low load profiles corresponding to the cessation of work activity for the summer holidays. In a scenario in which the load level remains similar across the summer season self-sufficiency increases to $40-50 \%$ including battery support. The corresponding economic performance is always remarkable, with IRR values in the range of 6$11 \%$.

\section{References}

1. T. Markvart, Solar Electricity, John Wiley and Sons Ltd, (2000).
2. K. P. Bhandari, J. M. Collier, R. J. Ellingson, D. S. Apul, Energy payback time (EPBT) and energy return on energy invested (EROI) of solar photovoltaic systems: A systematic review and metaanalysis, Renewable and Sustainable Energy Reviews," 47, 133-141 (2015):

3. W. F. Pickard, A simple lower bound on the EROI of photovoltaic electricity generation, Energy Policy, 107, 488-490 (2017).

4. PV polysilicon weekly spot prices, [Online]. Available: http://pvinsights.com/ [Access date: 28 February 2018].

5. BloombergNEF, New Energy Outlook 2018 [Online]. Available: https://about.bnef.com/newenergy-outlook/\#toc-download [Access date: 10 November 2018].

6. M. Liebreich, Dissertation at the opening of the "Bloomberg New Energy Finance Summit 2015, New York [Online]. Available: https://sitecstatement.files.wordpress.com/2016/02/4 4-bloomberg-new-energy-finance-april-2015bloomberg-new-energy-finance-summit.pdf [Access date: 28 February 2018].

7. Lazard, Levelized Cost of Energy and Levelized Cost of Storage 2018 [Online]. Available: https://www.lazard.com/perspective/levelized-costof-energy-and-levelized-cost-of-storage-2018/ [Access date: 10 November 2018].

8. Renewable energy Policy network (REN21), Renewables 2018 Global Status Report [Online]. Available:: $\quad$ http://www.ren21.net/status-ofrenewables/global-status-report/ [Access date: 10 November 2018].

9. F. Spertino, J. Ahmad, A. Ciocia, P. di Leo, How much is the advisable self-sufficiency of aggregated prosumers with photovoltaic-wind power and storage to avoid grid upgrades?, 2017 IEEE Industry Applications Society Annual Meeting, Cincinnati, OH, 2017, pp. 1-8.

10. F. Spertino, J. Ahmad, A. Ciocia, P. di Leo, F. Giordano, Maximization of self-sufficiency with grid constraints: $P V$ generators, wind turbines and storage to feed tertiary sector users, 2017 IEEE 44th Photovoltaic Specialist Conference, Washington DC, pp. 3096-3101.

11. Italian Transmission System Operator (TERNA), "Trend of the electricity demand in real time," 2018. [Online]. Available: http://www.terna.it/SistemaElettrico/StatisticheePr evisioni/DatiStatistici.aspx [Access date: 10 November 2018].

12. A. Carullo, A. Castellana, A. Vallan, A. Ciocia, F. Spertino, Uncertainty issues in the experimental assessment of degradation rate of power ratings in photovoltaic modules, Measurement, 111, 432-440 (2017).

13. A. Ciocia et al., Voltage control in low voltage grids: A comparison between the use of distributed photovoltaic converters or centralized devices, IEEE International Conference on Environment and Electrical Engineering and 2017 IEEE Industrial and 
Commercial Power Systems Europe (EEEIC / I\&CPS Europe), Milan, 2017, pp. 1-6.

14. F. Spertino, P. Di Leo, F. Corona and F. Papandrea, Inverters for grid connection of photovoltaic systems and power quality: Case studies, 3rd IEEE International Symposium on Power Electronics for Distributed Generation Systems (PEDG), Aalborg, 2012, pp. 564-569.

15. F. Spertino, G. Chicco, A. Ciocia, G. Malgaroli, A. Mazza and A. Russo, Harmonic distortion and unbalance analysis in multi-inverter photovoltaic systems, 2018 International Symposium on Power Electronics, Electrical Drives, Automation and Motion (SPEEDAM), Amalfi, 2018, pp. 1031-1036.

16. U.S. Energy Information Administration, Levelized Cost and Levelized Avoided Cost of New Generation Resources in the Annual Energy Outlook 2016 [Online]. Available: http://www.eia.gov/outlooks/aeo/pdf/electricity gen eration.pdf [Access date: 10 November 2018].

17. A. Ciocia, J. Ahmad, G. Chicco, P. Di Leo e F. Spertino, Optimal Size of Photovoltaic Systems with Storage for Office and Residential Loads in the Italian Net-Billing Scheme, in UPEC2016, Coimbra, Portugal, 2016.

18. A. Oudalov, ABB Switzerland, Corporate Research, Energy Storage in Electric Power Systems Integration of Renewable Energy Sources, Ispra, 2015.

19. Italian Energy Services Operator, Gestore servizi energetici (GSE) [Online]. Available: http://www.gse.it/ [Access date: 28 February 2019].

20. Danish Wind Energy Associates (DWEA), 2016. [Online]. Available: www.windpower.org [Access date: 28 February 2019].

21. F. Spertino, P. Di Leo, I. S. Ilie, G. Chicco, DFIG equivalent circuit and mismatch assessment between manufacturer and experimental power-wind speed curves, Renewable Energy, 48, 333-343 (2012).

22. F. Spertino, A. Ciocia, P. Di Leo, R. Tommasini, I. Berardone, M. Corrado, A. Infuso, M. Paggi, A power and energy procedure in operating photovoltaic systems to quantify the losses according to the causes, Solar Energy, 118, 313-326 (2015). 